\title{
Study of a Combined Controller of Power System Stabilizer and Wind Turbine Drive-train Damping Filter
}

\author{
Fan Zhang ${ }^{1, a^{*}}$ \\ ${ }^{1}$ A410, SGCC Park, Future Tech City, Beijing, China \\ azhangfan@sgeri.sgcc.com.cn,
}

Keywords: Doubly-fed induction generator, Power system stabilizer, Drive-train damping filter, Small signal stability, Fault ride-through.

Abstract. A coordinated power system stabiliser (PSS) design for wind turbine equipped with doubly-fed induction generator (DFIG) is presented in this paper. It is shown that the proposed control scheme enables the optimal performance for both the wind turbine structural loads damping and the power system damping. The interaction between wind turbine controller and PSS is studied by simulation. A holistic model including both the wind turbine and the electric network dynamics is employed for the assessment of controller performance. The influence of PSS control on wind turbine drive-train and tower are demonstrated. A generic network model is used to test the contribution that wind farm can make to the power system damping. It is shown that wind turbine is capable of providing similar damping response as synchronous generator do with acceptable increase of structural loads.

\section{Introduction}

The increasing of the penetration level of wind power is significantly influencing the power system transient stability. Currently the most widely used scheme of wind energy generation system is variable speed wind turbine with DFIG. Such configuration decouples wind turbine from grid by power electronics. Induction generator, which was the most common choice of wind energy generation before DFIG, acts as a damper when it is directly connected to the grid. The indirect connection between wind turbine and power system on DFIG wind turbine raises the problem of lack of damping to power system oscillation. To maintain the small signal stability of a power system, a certain amount of damping is required. Synchronous generator in conventional power plant provides damping to power system through PSS. With the integration of wind power, the damping from these power plants may not be sufficient to keep the power system operation within stability margin. It is desired that wind turbine can also provide damping to power system oscillation thus allowing more wind energy to be integrated to electric network.

PSS on synchronous generator is a typical and efficient mean of increasing the damping level of power system. It manipulates the excitation system of synchronous generator to produce the damping torque in reaction to power system oscillation. PSS widely exists in current power systems playing an important role to reduce the power oscillations and increase power system stability. Apparently the damping effect from PSS would be lost if these generators are replaced by wind power. To provide wind turbine with PSS function will significantly increase the compatibility between wind power and grid.

The DFIG can be used to enhance power system damping as presented in [4-6] [10-12]. Different implementations of PSS or controller that provides DFIG with similar capability are presented. However, only the dynamics of DFIG is considered in these studies. It is noticed that the control of generator reaction torque also affects the wind turbine controller and the load on wind turbine components. It is essential to include the wind turbine side into the design process of PSS for DFIG.

It is the objective of this paper to design a controller which enables DFIG to contribute to power system damping with limited extra loads on wind turbine. The goal is achieved by modifying existing wind turbine controller. The advantage of implementing the controller on wind turbine side rather than DFIG side is that the PSS is within the wind turbine control loop therefore the interaction 
between wind turbine and PSS can be easily assessed so the performance of both controllers are guaranteed.

This paper is organized as follows: First section introduces the background and objective of the paper. The next section shows the modelling of the wind turbine, DFIG and a generic network which are conducted for the simulation of proposed controller.The next section examines the influence of having PSS on wind turbine. The following describes the combined design of PSS and wind turbine controller. The last section shows the case study result by simulation in MATLAB/Simulink and the results are discussed.

\section{Modelling}

DFIG modelling. The modelling of DFIG has been well presented in the literature. One of the most widely used control scheme for DFIG is the so-called current mode control as described in [2]. In this research the dynamic model of a third order asynchronous generator with the controller is constructed in Simulink. The model is built in a synchronous frame fixed to the stator flux of the generator. The control of active and reactive power is fully decoupled therefore the manipulation of generator torque which is required by PSS operation would not influence the voltage control. This is one of the advantages of implementing PSS on DFIG over on synchronous generator as AVR on synchronous generator reduces the overall damping from the generator and require additional damping from PSS.

Drive-train and drive-train damping filter modelling. The full dynamic model of the wind turbine with its controller is described in [8] and [9]. A 2MW variable speed pitch regulated wind turbine and its control system is built in Simulink. The main concern of this paper in terms of wind turbine model is the drive-train system and the drive-train damping filter (DTD).

The drive-train connects the mechanical and electrical sides of wind turbine therefore torque variation from both sides add loads on the drive-train. As one of the most vulnerable part on wind turbine, the drive-train needs to be replaced several times during a wind turbine's lifetime because of the fatigue loads. Reduction of the drive-train loads can prolong its lifetime and reduce the overall cost of wind turbine. It is important to take drive-train load into consideration when applying device that changes generator reaction torque to wind turbine such as PSS.

Wind turbine drive-train is composed by rotor hub, low speed shaft, gearbox, high speed shaft and generator rotor. The aerodynamic torque produced by wind turbine on the low speed end of the drive-train is balanced by the generator reaction torque on the other end of the drive-train. The dynamics of the drive train are described by equation (1)

$\mathrm{I} \theta^{\prime \prime}=\mathrm{T}-\mathrm{T} 1-\gamma \theta^{\prime}$

where $\mathrm{T}$ and $\mathrm{T} 1$ are the hub torque and gear box torque at the low speed shaft end. I is the hub inertia plus the low speed shaft inertia, and $\theta$ is the angular displacement of the hub.

In a fixed speed wind turbine with synchronous generator, the grid provides damping to the generator rotor. Hence the damping for the wind turbine drive-train is satisfactory. In variable speed wind turbine induction machine is used so the damping from the grid is lost. The first drive-train mode is very lightly damped. Since the first drive-train mode is very resonant, the lack of damping can lead to very large torque oscillation which affects the turbine life time and safety.

The increase of the damping at first drive-train mode is achieved by feeding back the variation of the generator speed at the first drive-train mode frequency to the torque demand. The drive-train damping filter creates a damping torque which is proportional to the drive-train speed change. Essentially this approach employs the wind turbine dynamic to damp the first drive-train mode. The block diagram is shown if Fig. 1. 




Fig. 1 Drive-train damping filter

The drive-train damping filter is actually a band-pass filter. The frequency of the filter is not necessarily the first drive-train frequency as the gain of the plant at the first drive-train frequency is very high. Therefore, even if the filter frequency is biased a little, it is still able to filter the first drive-train mode properly.

Electrical system modelling. The PSS for DFIG described in [13] is employed to test the effect of PSS has on wind turbine mechanical system. The PSS has similar form and function as conventional PSS for synchronous generator and appears as an auxiliary control loop added to DFIG torque controller.

The power system model used in this research to examine the performance of the proposed controller has similar layout as the generic network described in [1]. It is essentially a 3 area power system. Area 1 modelled by a 6th order synchronous generator represents the large system. Area 2 modelled by a synchronous generator with PSS and AVR represents a conventional power plant. Area 3 is the wind farm with DFIG type generator. The diagram of the network model is shown in Fig. 2.

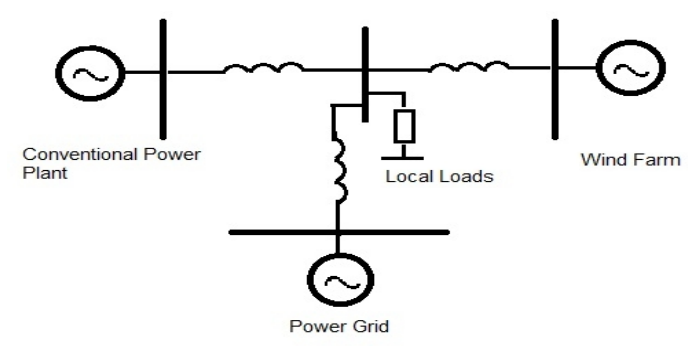

Fig. 2 Generic electrical network

\section{Influence of PSS on wind turbine}

Power system stabilizer generates damping torque against oscillations in power system including rotor speed, frequency and power variation. However from the perspective of wind turbine control, this additional damping torque is a disturbance which causes the excursion of rotor speed from maximum power tracking curve and introduces extra loads on drive-train, blades and tower. The influence of having PSS on wind turbine has to be investigated. The model with only wind turbine and DFIG is used to carry out the fault study. A 50\% voltage drop right at the PCC of wind turbine is applied for 700ms according to the fault ride-through requirement of UK grid code. The PSS starts to try to damp out the local oscillation caused by the fault when the fault is cleared and circuit breaker reclosed. The responses of wind turbine are shown mechanically and electrically in Fig. 3-6. 




Fig. 3: Generator speed during fault

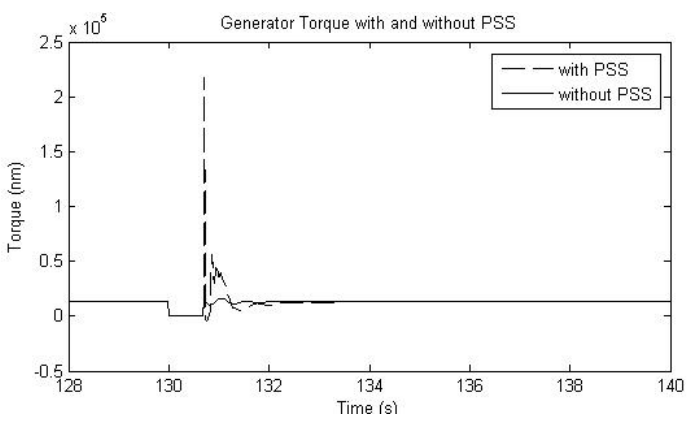

Fig. 4: Generator torque during fault

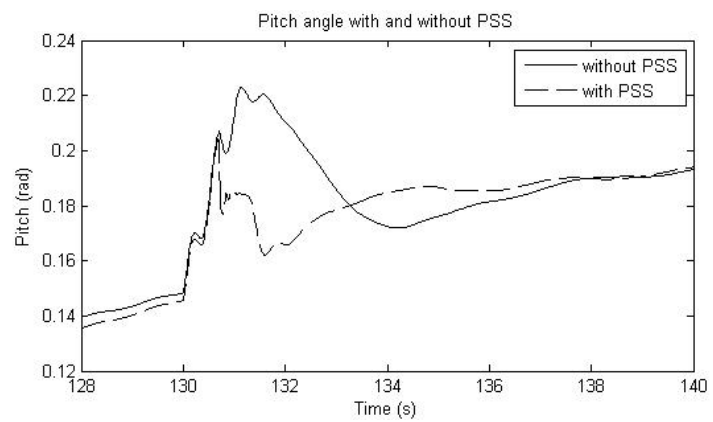

Fig. 5: blade pitch angle during fault

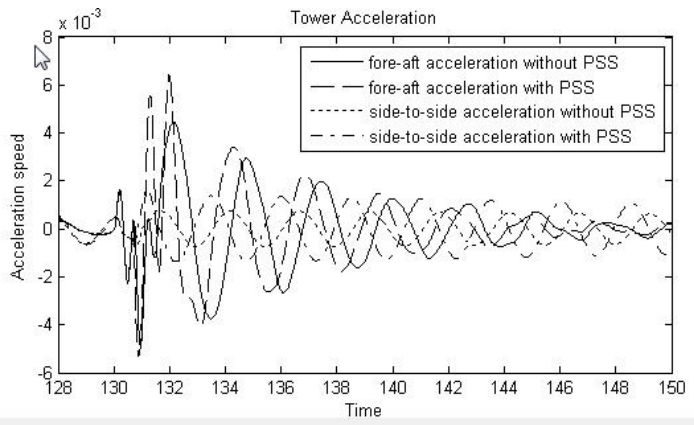

Fig. 6: Tower acceleration during fault

It can be seen from the result that PSS effectively suppressed the local drive-train speed fluctuation. However, the torque demanded by PSS controller is large compared to normal operational 
torque level even if a reasonable threshold is applied on PSS. The extreme torque occurs at the point of fault clearance which may cause the wind turbine emergency shut-down. The reconnection of the generator stator circuit to grid and the kick in of PSS lead to torque impulse which causes a sudden drop of wind turbine high speed shaft rotational speed. The wind turbine rotational speed oscillation is stabilized a little faster at the cost of high extreme load which is highly undesirable from the mechanical perspective of wind turbine. It is also noticed that because the PSS employs electrical torque to reduce the rotor speed excursion, the duty of pitch control to regulate speed variation is reduced as shown in Figure 5. The result implies the possibility of using wind turbine pitch control to realize the PSS function. In small scale wind turbines the blades are stronger than drive-train thus using blades rather than drive-train for damping power system oscillation can extend the drive-train lifetime and therefore reduce the maintenance fee. The additional loads on tower caused by PSS are also assessed. It can be seen that the tower loads is slightly increased when including PSS. The side-to-side acceleration is influenced more by PSS than fore-aft acceleration. However, the tower is affected less compared to other wind turbine components and the loads on tower are within acceptable range.

According to the case study result, it is clear that PSS has negative influence on most of wind turbine components especially the drive-train system. A combined PSS controller considering both the wind turbine and power system damping is needed.

\section{PSS installed on wind turbine}

PSS and wind turbine control. Wind turbine drive-train is naturally very lightly damped as it is normally made of steel and without any damping element. The first drive-train mode is very likely to be excited by the wind field going through rotor plane. It is normal nowadays to have the drive-train damper in wind turbine controller. The damper reduces drive-train oscillation by feeding the generator speed variation back to the generator torque. To avoid influencing the controller performance on other frequency, a band-pass filter is included to make sure only speed variations around drive-train frequency are fed back so the damper is also referred to as drive-train damping filter. The drive-train damper uses the generator torque to provide damping. The operation of drive-train damper does not strongly affect torque control loop as the torque required by the damper is relatively small.

PSS works in similar manner as drive-train damping filter. Although there are various types of PSS to accommodate different situations, the most widely used is the one based on generator speed variation. This type of PSS also feeds generator speed variation to torque demand. Instead of filtering the speed signal, PSS has a phase compensator as synchronous generator excitation system is nonlinear and shows phase characteristics. By adding this phase shifter the PSS generates pure damping torque. The torque-speed characteristic of induction generator is different from synchronous generator as shown in Fig. 7.

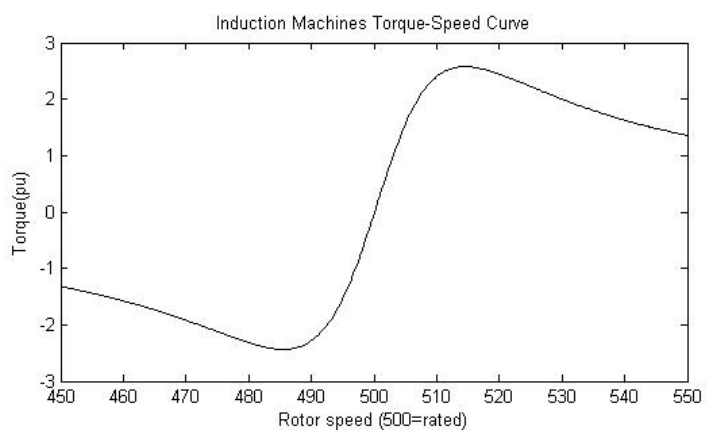

Fig. 7: Induction machine torque-speed curve 
The typical operational slip region for DFIG is from -0.25 to 0.25 which is $495-505$ in Figure 7 . It can be observed that within this region the relationship between generator speed and torque is almost linear. From [2] it can be seen that the DFIG torque controller is also linear. Hence the PSS for DFIG does not require phase compensation as do on synchronous generator. The damping torque can be produced by simply adding slip variation to torque control loop as an auxiliary loop. This PSS is a simplified version of the one shown in [5] and have almost same behavior.

Since the PSS and DTD shares similar form, it is possible to combine them together by moving the PSS to wind turbine control loop. Both torque controller and pitch controller can be employed to generate stabilizing torque to grid.

Combined PSS and DTD. PSS and DTD both generates damping torque but to different target. The PSS aims to alleviate the power oscillation in the grid while the DTD focus on the local drive-train oscillation. The main difference between these two oscillations modes is the frequency. Power system oscillation that PSS tries to suppress is normally from $0.1 \mathrm{~Hz}$ to $2 \mathrm{~Hz}$ [7]. The drive-train frequency of a $2 \mathrm{MW}$ wind turbine is around $2 \mathrm{~Hz}$. If a PSS which covers the whole power system oscillation frequency continuously operates on a wind turbine, the low frequency damping torque it produces would significantly affect the wind turbine controller. The maximum power tracking will be influenced and the wind turbine will no longer be able to track its operation curve.

To avoid affecting wind turbine controller operation, the PSS can only be designed to work within certain frequency range and only work during large power oscillation. The PSS proposed in this paper is designed to generate a torque component proportional to the generator speed variation. The frequency range of generator speed variation seen by the PSS is limited by a band pass filter sitting on the oscillation frequency of the connected power system. The filter has the form as in equation (2)

GPSS $=$ Ks $(\mathrm{s} 2+2 \zeta \omega n+\omega n 2)-1$

where $\mathrm{K}$ is the PSS gain, $\omega \mathrm{n}$ is the power system oscillation frequency, and $\zeta$ defines the speed of the gain dropping with frequency change.

The switching of the PSS is controlled by the power system frequency deviation. The drive-train damping filter is constantly working as GDTR. When large oscillation is detected in the grid, the PSS kicks in and the drive-train damping filter becomes GPSS+ GDTR. The bode plot of the combined PSS and DTD is shown in Fig. 8.

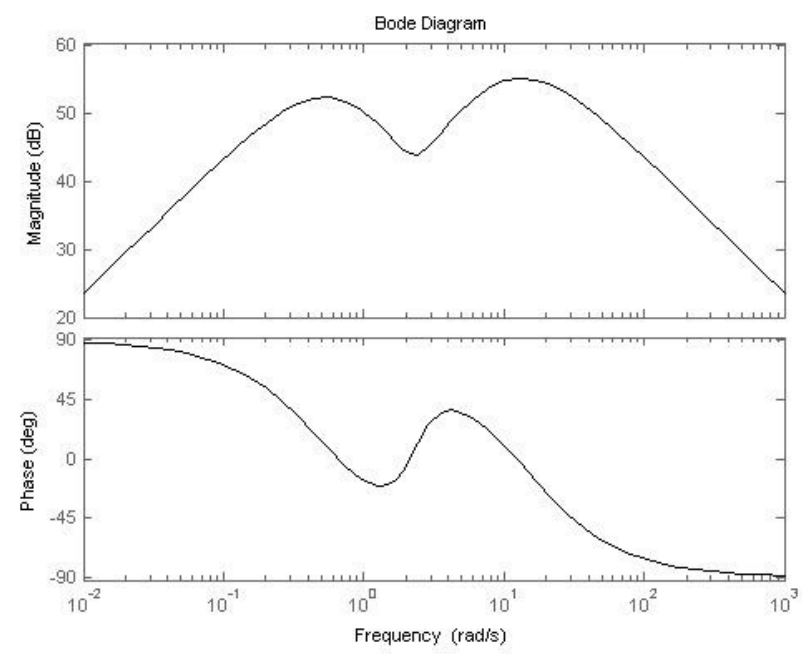

Fig. 8: bode diagram of proposed controller 
PSS by pitch control. The proposed PSS filter can also work in the pitch control loop of the wind turbine controller. Pitching is a more powerful and effective mean in terms of regulating power system oscillation as it changes the mechanical torque input actively. However, pitch control should be used very carefully as it strongly affects the wind turbine control strategy and may lead to instability. Such method should only be used when damping of power system has higher priority than the maximum energy extraction of wind turbine.

The choice of using drive-train or blade to produce damping torque is also affected by the wind turbine characteristic. The size of the wind turbine is the main concern. The larger the wind turbine, the less fatigue loads is allowed on blades as the size of it increases dramatically with wind turbine size while the drive-train load does not vary much.

\section{Simulation result}

A case study is carried out to investigate the performance of the proposed PSS by time domain simulation. The wind power penetration level is set to be $20 \%$ of the overall capacity of the test power system. At $150 \mathrm{~s}$ a fault lasting $150 \mathrm{~ms}$ occurs causing the disconnection of the power plant and the whole system loses $40 \%$ of its overall generation. The transient response of the grid and wind turbine is shown in Fig. 9 and Fig. 10.

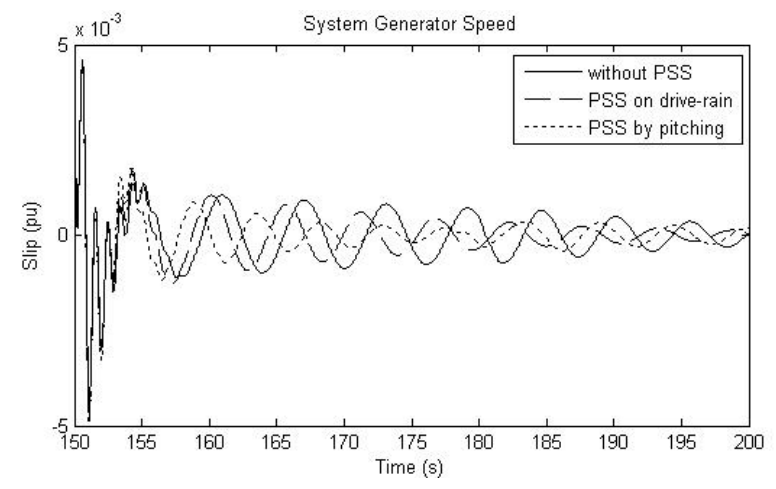

Fig. 9: System generator speed

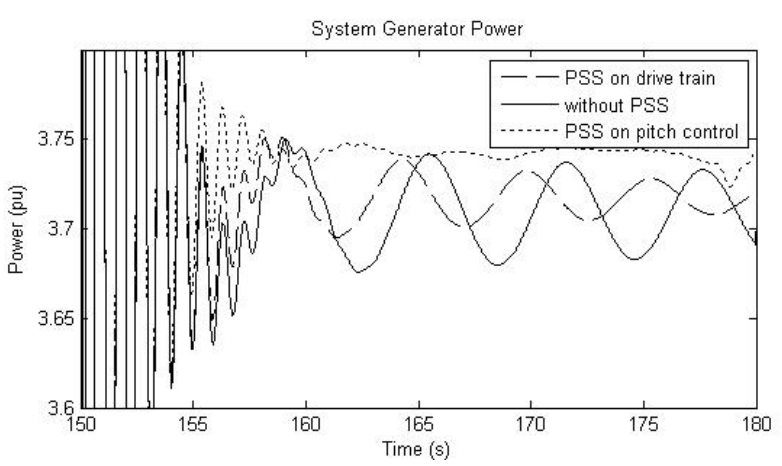

Fig. 10: system generator power

The transients of the power and frequency of the system generator after the fault are shown in Figure 9 and 10. The speed fluctuation, which is the representation of system frequency oscillation, is effectively alleviated by the damping power generated by the wind farm. It can be seen that the PSS using wind turbine pitch is more efficient in suppressing frequency oscillation than the one using wind turbine drive-train mechanics. However, Figure 11 shows that the increased damping is at the 
cost of the drop of wind power production and rotor speed oscillation. The power production of the system generator shows that the power fluctuation is reduced with the assist of PSS on wind turbine.

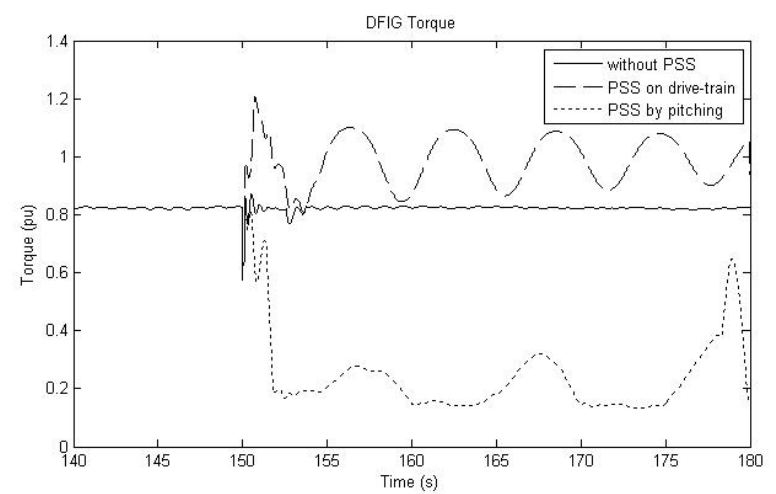

Fig. 11: DFIG torque during fault

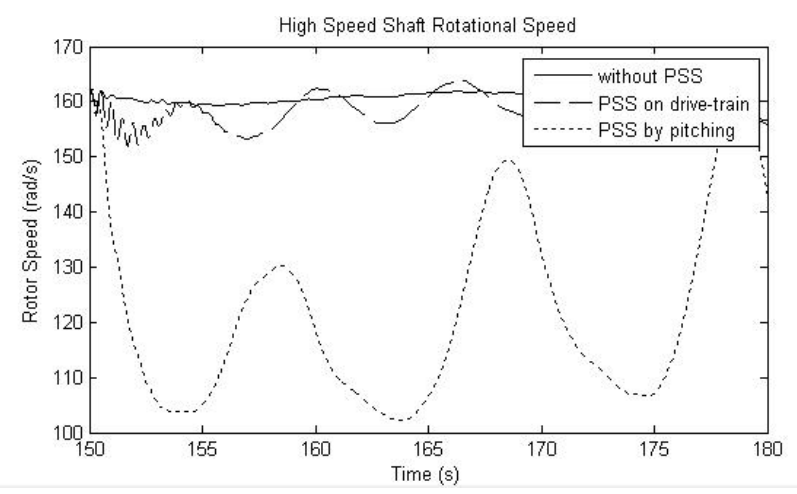

Fig. 12: Generator speed during fault

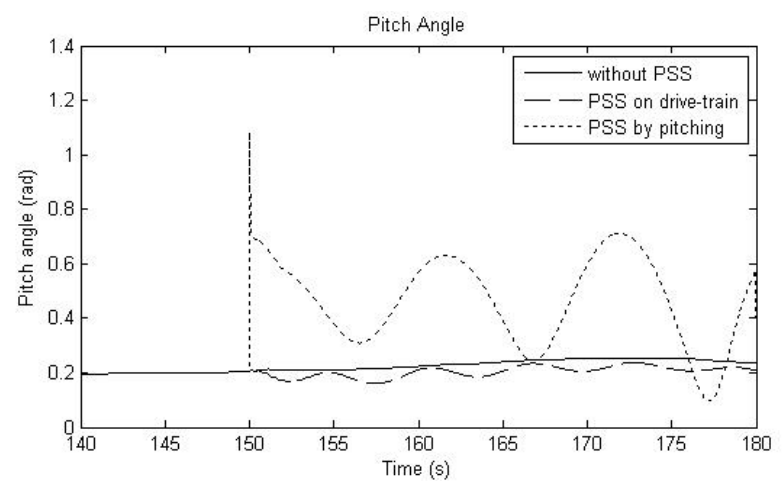

Fig. 13: Blade pitch angle during fault

The wind turbine dynamic response during the PSS operation is shown in Fig. 11-13. The PSS on drive-train causes small disturbance on wind turbine rotor speed and blade pitch angle while the PSS installed in pitch control loop produce stronger damping but has larger influence on the wind turbine operation and increased the loads on both the wind turbine drive-train and blade.

It is shown that the generator torque and speed oscillation amplitude are suppressed comparing to the fault study. The extreme load on wind turbine drive-train is reduced from about 10 times the rated load to about 20\% for drive-train based PSS and $80 \%$ for pitch based PSS. 
As the power system oscillation contains low frequency components, the injection of this signal into wind turbine control loop lead to the excursion of wind turbine from its optimum torque-speed operation curve as seen in Figure 11 and 12. Considering the short time and relatively low frequency of power system oscillation event, the wind turbine is still a valid option to provide damping to power system

\section{Conclusion}

A wind turbine based PSS has been presented in this paper. The PSS is designed for variable speed wind turbine equipped with DFIG. The proposed PSS is shown to be able to produce damping to power system oscillation as the conventional PSS installed on synchronous generator. The realization of PSS using different wind turbine components, namely drive-train and pitch, are examined. It is found that stabilization by pitching is more effective but causes more structural loads on wind turbine. The drive-train is also able to produce damping to power system but the contribution is smaller with fixed mechanical power input.

It is presented by the case study that the use of PSS on wind turbine contributes to the power system stability therefore reduces the need for damping from synchronous generators. The issue of the lack of damping to power system from wind turbine that limits the large scale integration of wind power can be solved by providing wind turbine with PSS facility.

\section{References}

[1] Olimpo Anaya-Lara, M. Hughes, and N. Jenkins, "Generic network model for wind farm control scheme design and performance assessment," in Proc. Eur. Wind Energy Conf., London, UK, 2005.

[2] Olimpo Anaya-Lara, F. Michael Hughes, Nicholas Jenkins, Goran Strbac, "Rotor flux magnitude and angle control strategy for doubly fed induction generators," Wind energy. 2006; 9: 479-495.

[3] E. A. Bossanyi, The Design of Closed-loop Controllers for Wind Turbines, Wind Energy, vol. 3, 2000, pp. 149-163.

[4] R. D. Fernández, R.J. Mantz and P.E. Battaiotto "Wind farm control for stabilisation of electrical networks based on passivity," International Journal of Control, 83:1, 105-114

[5] F. M. Hughes, O. Anaya-Lara, N. Jenkins, and G. Strbac, "A power system stabilizer for dfig-based wind generation,” IEEE Trans. Power Syst., vol. 21, no. 2, pp. 763-772, May 2006.

[6] P. Ledesma and C. Gallardo, "Contribution of variable-speed wind farms to damping of power system oscillations,” in Proc. of IEEE PowerTech, Lausanne, Switzerland, July 2007.

[7] P. Kundur, Power System Stability and Control. New York: McGrawHill, 1994.

[8] W.E. Leithead and M.C.M. Rogers, "Drive-train characteristics of constant speed HAWTs," Wind Engineering. Vol 20. No. 3, 1996

[9] W. E. Leithead and B. Connor, Control of variable speed wind turbines: dynamic models, INT. J. CONTROL, 2000, VOL. 73, NO. 13, 1173 \pm 1188

[10] Â Mendonça, and J. A. Peças Lopes, "Simultaneous Tuning of Power System Stabilizers Installed in DFIG-Based Wind Generation," Power Tech, 2007 IEEE Lausanne, pp. 219 - 224, 1-5 July 2007

[11] Z. Miao, L. Fan, D. Osborn, and S. Yuvarajan, "Control of dfig-based wind generation to improve interarea oscillation damping," IEEE Trans. Energy Conversion, vol. 24, no. 2, pp. 415-422, June 2009. 
[12] G. Tsourakis, B. M. Nomikos, and C. D. Vournas, "Contribution of doubly fed wind generators to oscillation damping," IEEE Trans. Energy Conversion, vol. 24, no. 3, pp. 783-791, Sept. 2009.

[13] F. Zhang, W.E. Leithead, and O. Anaya-lara, "Wind Turbine Control Design to Enhance the Fault Ride-Through Capability,” IET Conference on Renewable Power Generation, pp. 11, Sept 2011 